\title{
COMPRAVENTA INTERNACIONAL DE MERCADERÍAS: EL DEBER DE RENEGOCIACIÓN EN CASO DE EXCESIVA ONEROSIDAD SOBREVENIDA
}

INTERNATIONAL SALE OF GOODS: THE OBLIGATION TO RENEGOTIATE IN THE CASE OF SUPERVENING CHANGE IN CIRCUMSTANCE

\section{COMPRA-VENTA INTERNACIONAL DE MERCADORÍAS: O DEVER DE RENEGOCIAÇÃO EM CASO DE EXCESSIVA ONEROSIDADE SOBREVINDA}

Rodrigo Momberg Uribe

\section{RESUMEN}

El trabajo analiza desde la perspectiva del Derecho Uniforme contenido en la Convención de Viena sobre Compraventa Internacional de Mercaderías, la existencia del deber de renegociar el contrato en caso de hardship o excesiva onerosidad sobrevenida, sobre la base de la aplicación de los Principios UNIDROIT sobre Contratos Comerciales Internacionales por la vía del artículo 7.2 de la Convención, que regula los mecanismos de integración de la misma. Se concluye la conveniencia de tal interpretación, la cual constituye, además, una alternativa interesante para el Derecho nacional en la materia.

${ }^{*} \mathrm{PhD}$, Universidad de Utrecht. Profesor de Derecho Civil, Universidad Austral de Chile. Honorary Lecturer, Instituto Molengraaff de Derecho Privado, Universidad de Utrecht. Dirección postal: Universidad Austral de Chile Facultad de Ciencias Jurídicas y Sociales, Campus Isla Teja s/n, Valdivia, Chile. Artículo recibido el 3 de noviembre de 2011 y aceptado para su publicación el 7 de marzo de 2012. Correo electrónico: rmomberg@uach.cl 


\begin{abstract}
The paper analyzes the obligation to renegotiate a contract in the case of hardship or supervening change in circumstance from the perspective of the uniform law of the Vienna Convention on Contracts for the International Sale of Goods and specifically the application of the Unidroit principles on International Commercial Contracts contained in Article 7(2) of said convention on the integration of those principles. The paper concludes that such an approach is appropriate and serves as an attractive option for domestic Chilean law in this field.
\end{abstract}

Keywords: hardship, unforeseen contingencies, negotiation, contracts, Vienna Convention on International Sale of Goods.

\title{
Resumo
}

O trabalho analisa a perspectiva do direito uniforme contido na Convenção de Viena sobre Compra-venta Internacional de Mercadorías, a existência do dever de renegociar o contrato em caso de hardship ou 96 excessiva onerosidade sobrevinda, com base à aplicação dos Principios UNIDROIT sobre Contratos Comerciais Internacionais pela vía do artigo 7.2 da Convenção, que regula os mecanismos de integração da mesma. A conveniência de tal interpretação se constitui em uma alternativa interessante para o direito nacional na matéria.

Palavras chave: excessiva onerosidade, renegociação, contratos, Convenção de Viena sobre Compra-venta Internacional de Mercadorias.

\section{INTRODUCCIÓN}

Las situaciones de cambio de circunstancias son frecuentes en materia de contratación internacional. Fenómenos como la globalización, los avances en las comunicaciones y el transporte, y la evidente interrelación entre los mercados, hacen que los contratos internacionales, en especial aquéllos que implican un tiempo prolongado de ejecución, se encuentren hoy sujetos a un gran número de vicisitudes y contingencias que en muchos casos van más allá de lo que las partes pudieron razonablemente prever al tiempo del contrato. El tema por cierto está lejos de ser pacífico, y así, tanto en el Common Law como en el Derecho Civil o Continental la cuestión ha sido objeto de amplio debate doctrinario y jurisprudencial, sin perjuicio 
de que modernos instrumentos internacionales de soft law o codificaciones doctrinales ${ }^{1}$ como los Principios UNIDROIT parezcan marcar una tendencia hacia su reconocimiento como excusa para la parte afectada, concediendo, al mismo tiempo, amplias facultades al juez para adaptar o terminar el contrato según sea más adecuado en el caso particular ${ }^{2}$.

El presente trabajo analiza la cuestión a partir de una sentencia de la Corte de Casación Belga (Hof van Cassatie), que reconoce la aplicación en general de los Principios UNIDROIT a contratos regulados por la Convención y, en particular, establece la existencia de un deber de renegociación entre las partes en caso de hardship, excesiva onerosidad o cambio de circunstancias (términos que se usarán como sinónimos), con base también en tales Principios. La sentencia presenta interés ya que emana de un máximo tribunal y se refiere a dos cuestiones debatidas en doctrina: el mecanismo de integración de la Convención y la posibilidad de alegar un cambio de circunstancias como excusa en un contrato regido por ella. Por ello, puede constituir un precedente relevante en futuras disputas relativas a la aplicación de la Convención en casos de cambio de circunstancias, y aún más importante, para determinar los remedios disponibles para las partes en tales situaciones.

Para el análisis de la materia, en la sección II se efectúa una breve descripción del caso, para continuar con el estudio de las reglas de integración de la Convención (III), su sistema de excusas (IV) y la eventual regulación del cambio de circunstancias en la Convención (v). Posteriormente, se analiza el deber de renegociación en los Principios UNIDROIT (vI), para terminar con las conclusiones y eventuales consecuencias para nuestro Derecho interno (VII).

\section{II.- EL CASO ${ }^{3}$}

Los hechos del caso son los típicos de una situación de excesiva onerosidad sobrevenida. Las partes concluyeron una serie de contratos de compraven-

${ }^{1}$ Codificaciones doctrinales o no legislativas son aquéllas que han sido redactadas independientemente o con autonomía del poder soberano y político de un país o jurisdicción, por lo que carecen de fuerza obligatoria en tal ordenamiento. Véase Nils JANSEN, The making of legal authority: non-legislative codifications in historical and comparative perspective, Oxford, Oxford University Press, 2010, p. 7.

${ }^{2}$ Véanse los artículos 6.2.1 a 6.2.3 de los Principios UNIDROIT, 6:111 de los PECL y III 1:110 del DCFR.

${ }^{3}$ Scafom International BV vs. Lorraine Tubes S.A.S; $\mathrm{N}^{\circ}$ C.07.0289.N, sentencia de fecha 19 de junio de 2009, Corte de Casación belga, en http://cisgw3.law.pace.edu/cases/ 090619b1.html. 
ta, obligándose el vendedor a entregar tubos de acero por un precio fijo, sin que se incluyera una cláusula de revisión del mismo. Con posterioridad a la celebración de los contratos, el precio del acero se incrementó imprevista y súbitamente en más de un 70\%. Debido al aumento de costos, el vendedor (una empresa francesa), requirió la adaptación del precio a las nuevas circunstancias, pero el comprador (una empresa holandesa), rechazó todas las propuestas de modificación, insistiendo en el cumplimiento del contrato en sus términos originales, y demandando, en definitiva, al vendedor la indemnización de perjuicios producida por el incumplimiento de contrato. A su vez, el vendedor demandó el ajuste del precio basado en el imprevisto y drástico incremento en los costos. En procedimiento sumario, se ordenó al vendedor la entrega de los bienes contra el pago del precio acordado, más la mitad del incremento demandado.

En cuanto al fondo del asunto, en primera instancia el Juzgado Comercial de Tongeren rechazó la demanda de adaptación del precio, pues consideró que las situaciones de excesiva onerosidad no estaban reguladas ni regidas en el artículo 79 de la Convención ni en ninguna otra de sus normas. En segunda instancia, la Corte de Apelaciones de Amberes revocó la sentencia, señalando que la existencia de una norma explícita para los casos de fuerza mayor (el artículo 79 de la Convención) no implicaba la exclusión de la posibilidad de invocar la excesiva onerosidad por las partes. La Corte de Apelaciones agregó que la petición de adaptación del precio basada en hardship no es contraria a los Principios en los cuales se funda la Convención, pero ya que tal situación es distinta a una de fuerza mayor, la controversia debía ser decidida en conformidad a la ley, aplicable según las normas de Derecho Internacional Privado (última parte del artículo 7.2). En el caso, resultaba aplicable el Derecho francés, de acuerdo con el cual la Corte estimó que el deber de ejecutar las convenciones de buena fe, incluido en la última aparte del artículo 1134 del Code Civil, impone a las partes el deber de renegociar los términos del contrato si un cambio imprevisible de circunstancias transforma el cumplimiento en injustamente oneroso para una de ellas ${ }^{4}$. Con estos fundamentos, la Corte determinó que la negativa del comprador a renegociar el precio implicaba una infracción al deber de buena fe, condenándolo a indemnizar perjuicios a favor del vendedor.

El comprador interpuso un recurso de casación contra la sentencia de segunda instancia, el cual fue rechazado por la Corte de Casación Belga,

${ }^{4}$ Al efecto, véase Cass. com., 3 November 1992, "arrêt Huard", D. 1995, Somm. p. 85, note D. Ferrier; Cass. com. 24 November 1998, "arrêt Chevassus-Marge", D. 1999, p. 9; Cass. civ. 16 March 2004, D. 2004 Somm. p. 1.754, note Denis Mazeaud; CA Nancy $2^{\text {a }}$ Ch. Com. 26 September 2007, La Semaine Juridique, No 20, Paris, 14 May 2008, p. 29. 
confirmándose la decisión de la Corte de Apelaciones, pero sobre la base de fundamentos distintos. Al efecto, la Corte de Casación señaló que el acaecimiento de circunstancias imprevisibles que causen una perturbación seria en el equilibrio del contrato puede constituir un impedimento en el contexto del artículo 79 de la Convención; agregando que sin perjuicio de ello, existe para estos casos en la Convención un vacío o laguna que debe ser integrado en virtud de los Principios generales del Derecho Comercial Internacional (7.2). La Corte señaló, además, que según éstos, en particular incorporados en los Principios UNIDROIT, la parte afectada por un cambio de circunstancias está facultada para solicitar la renegociación del contrato, confirmando la condena en perjuicios para el comprador, que se había negado a renegociar la adaptación del precio a las nuevas circunstancias.

\section{El SISTEMA DE INTEGRACIÓN DE LA CONVENCIÓN}

En teoría, el sistema de integración de lagunas o vacíos que contempla la Convención no presenta dificultades. En materias no expresamente reguladas por ella, pero que puedan entenderse incluidas en su ámbito material de aplicación, el artículo 7.2. dispone:

"Las cuestiones relativas a las materias que se rigen por la presente Convención que no estén expresamente resueltas en ella se dirimirán de conformidad con los Principios generales en los que se basa la presente Convención o, a falta de tales Principios, de conformidad con la ley aplicable en virtud de las normas de derecho internacional privado".

La Convención adopta un sistema de integración de lagunas de tipo ecléctico, con dos fuentes de integración de aplicación subsidiaria: los Principios generales en que se basa la Convención y en su defecto, el Derecho interno designado por la norma de conflicto ${ }^{5}$.

Por tanto, si una materia gobernada por la Convención (lo que implica que no ha sido rechazada o excluida por la misma) no se encuentra total o parcialmente regulada en ella, dicha materia debe resolverse remitiéndose, en primer lugar, a los Principios en los cuales la Convención se basa. La Convención entonces hace prevalecer su autointengración por sobre

${ }^{5}$ Álvaro VIDAL, "Integración de la Convención de Viena sobre Compraventa Internacional de Mercaderías", en Revista de Derecho PUCV, vol. xxiv, Valparaíso, 2003, p. 479. 
la heterointegración ${ }^{6}$. El problema se produce porque ésta no señala de forma expresa principio general alguno en el cual se funde ${ }^{7}$. Con excepción del principio de buena fe mencionado en el artículo 7.1, ha sido la doctrina la que ha propuesto algunos Principios generales, deducidos de la interpretación sistemática de las normas de la Convención como, por ejemplo, el de razonabilidad, el de favor contractus o el de mitigación ${ }^{8}$. Se ha agregado que tales Principios pueden no sólo deducirse de la Convención misma sino, también, de fuentes externas, cuando constituyan principios generalmente reconocidos del Derecho Comercial Internacional ${ }^{9}$. En este sentido, se ha considerado que los Principios UNIDROIT constituyen un instrumento adecuado para complementar y llenar los eventuales vacíos de la Convención. Se argumenta que el objetivo de uniformidad que ésta persigue y la tarea de los tribunales se facilita con el uso de los Principios UNIDROIT en el contexto del artículo $7.2^{10}$. Tal propósito se encuentra bien señalado en el preámbulo de los Principios UNIDROIT, que indica:

"Estos Principios pueden ser utilizados para interpretar o complementar instrumentos internacionales de derecho uniforme".

Se agrega que razones de equidad también aconsejan la utilización de los Principios UNIDROIT, ya que recurrir al Derecho uniforme resulta más justo para los intereses de ambas partes que recurrir a un derecho doméstico que puede beneficiar en mayor medida a sólo una de las partes ${ }^{11}$.

Sin perjuicio de lo indicado, la afirmación que los Principios UNIDROIT representan Principios generalmente aceptados en Derecho Comercial Internacional, debe ser ponderada respecto de ciertas materias. Los mismos establecen en su introducción que en algunas materias los textos adoptados fueron considerados la "mejor solución", aun cuando no fueran la norma o regla generalmente aceptada o adoptada en el comercio

${ }^{6}$ VIDAL (n. 5), p. 469.

${ }^{7}$ Sonja Kruisinga, (Non-) Conformity in the 1980 UN Convention on Contracts for the International Sale of Goods: A Uniform Concept?, Amberes, Intersentia Uitgevers NV, 2004, p. 18.

${ }^{8}$ Niklas Lindström, "Changed Circumstances and Hardship in the International Sale of Goods", in Nordic Journal of Commercial Law, Estambul, 2006, p. 20.

${ }^{9}$ Ibid.

${ }^{10}$ Michael J. Bonell, "The UNIDROIT Principles of International Commercial Contracts and CISG-Alternatives Or Complementary Instruments?", in Uniform Law Review, N ${ }^{\circ} 1,1996$, pp. 34-36.

${ }^{11}$ Alejandro M. Garro, "Gap-Filling Role of the Unidroit Principles in International Sales Law: Some Comments on the Interplay between the Principles and the CISG", in Tulane Law Review, No 69, New Orleans, 1994, p. 1.159. 
internacional ${ }^{12}$. En particular, la Convención de Viena fue un punto de referencia para el grupo de trabajo que redactó los Principios UNIDROIT, incluyéndose varias de sus normas en el texto de los Principios, pero, al mismo tiempo, el grupo de trabajo se apartó o modificó las reglas de la Convención cuando lo consideró adecuado ${ }^{13}$.

Lo anterior debe tenerse en cuenta especialmente en relación con la materia de cambio de circunstancias, ya que el enfoque de ambos instrumentos es completamente distinto, en especial respecto de los remedios estipulados por el artículo 79 de la Convención y el artículo 6.2.3 de los Principios. Además, no es claro que las normas en esta materia representen "Principios reconocidos internacionalmente", más aún si tomamos en cuenta las diferencias entre los sistemas del Common Law y el Derecho Civil a este respecto.

Así, el más problemático de los remedios para el caso de cambio de circunstancias, esto es, la adaptación del contrato por el juez, es completamente ajeno al sistema del Common Law. Así, pues, en el Common Law inglés, la denominada frustration ${ }^{14}$ tiene el único efecto de poner término al contrato desde el momento del acaecimiento del hecho que le dio lugar, liberando a ambas partes del cumplimiento de toda obligación pendiente. Además, ella opera de forma automática (de pleno derecho en nuestra terminología jurídica), sin consideración a la voluntad de las partes, pudiendo ser invocada por cualquiera de ellas indistintamente.${ }^{15}$ Consecuente con ello, el Common Law inglés no provee mecanismos para la adaptación o ajuste del contrato, de modo que en un caso de frustration cada parte soporta sus pérdidas sin derecho a indemnización de perjuicios ${ }^{16}$. Por otro lado, en el Derecho estadounidense, la doctrina que puede asimilarse

${ }^{12}$ UNIDROIT Principles, Introduction.

${ }^{13}$ Ibid. Véase también Scott D. Slater, "Overcome by Hardship: The Inapplicability of the UNIDROIT Principles' Hardship Provisions to CISG”, in Florida Journal of International Law, $\mathrm{N}^{\circ}$ 12, Florida, 1998, p. 231.

${ }^{14}$ En el Common Law inglés el término frustration of contract incluye al menos tres situaciones diferentes: el caso en que el cumplimiento ha devenido en física o legalmente imposible, aquél en que el cumplimiento se ha tornado extremadamente oneroso o dificultoso (impracticable) y en el que la contraprestación ha perdido su valor para el acreedor (frustration of purpose). Véase Andrew Kul,, "Mistake, Frustration, and the Windfall Principle of Contract Remedies", in Hastings Law Journal, No 43, London, 1991, p. 1 y Guenter Treitel, Frustration and Force Majeure, $2^{\mathrm{a}}$ ed, London, Sweet \& Maxwell Limited, 2004.

${ }^{15}$ Hugh G. Beale, William D. Bishop \& Michael P. Furmston, Contract, Cases and Materials, $4^{\text {a }}$ ed., London, Butterworths, 2001, p. 482 y Ewan MCKENDRICK, "Frustration and Force Majeure-Their Relationship and Comparative Assessment", in Ewan McKENDRICK (ed.), Force Majeure and Frustration of Contract, London, Lloyd's of London Press Ltd., 1991, p. 38. Para un análisis detallado véase Treitel (n. 14).

${ }^{16}$ Kull (n. 14), p. 18. 
a la excesiva onerosidad es la denominada commercial impracticability o simplemente impracticability, reconocida en el Uniform Commercial Code (sección 2-615) y en el Restatement (Second) de Contratos (\$261) 17. Ésta contempla una serie de remedios que permiten mitigar el efecto extremo de la terminación del contrato, que alguna doctrina, incluso, sobre la base del texto de los comentarios oficiales de las normas respectivas, han extendido al extremo de entender que se concede al juez la facultad de adaptar el contrato a las nuevas circunstancias ${ }^{18}$. Sin embargo, en la práctica la jurisprudencia ha sido extremadamente renuente a decretar la modificación del contrato en casos de impracticability, existiendo sólo un caso en ese sentido, Aluminium Co. of America vs. Essex Group, Inc. (el caso Alcoa) ${ }^{19}$, el cual no ha sido seguido por la jurisprudencia e, incluso, ha sido criticado de manera muy dura en fallos posteriores ${ }^{20}$.

$\mathrm{Al}$ contrario, la tendencia en los sistemas de Derecho Civil es a reconocer la excesiva onerosidad como excusa para el deudor afectado y, en particular, a establecer como remedios el deber (al menos implícito) de renegociación y la facultad del juez de adaptar el contrato. Así lo contemplan el artículo 6:258 del $B W$ y el $\S 313$ del $B G B$. Normas similares se incluyen en los Códigos de Portugal y Grecia. En Italia, la doctrina y la jurisprudencia han interpretado el artículo 1467 del Códice Civile en el sentido de otorgar al juez la facultad de adecuar el contrato a las nuevas circunstancias ${ }^{21}$. A su vez, la Corte de Casación francesa ha reconocido la existencia de un deber de renegociar los términos del contrato en casos de grave alteración del equilibrio económico entre las contraprestaciones ${ }^{22}$. En Latinoamérica, los Códigos Civiles de Argentina, Brasil, Paraguay y Perú, así como el Código de Comercio colombiano, reconocen de manera expresa la imprevisión contractual. La gran excepción a esta tendencia sigue siendo Chile.

Aparece aquí el primer aspecto interesante de la sentencia mencionada en la sección II. Tal como se señaló, la Corte de Casación belga, a conti-

${ }^{17}$ Impracticability es usualmente definida como una excusa para la parte afectada por un gravamen extremo, irrazonable e imprevisible en el cumplimiento de su obligación, causado por un hecho irresistible, Samuel Williston \& Richard A. Lord, Williston on Contracts in http://international.westlaw.com/find/default.wl?rs=WLIN10.08\&ifm= NotSet\&fn=_top\&sv $=$ Split\&findjuris $=00001 \& \mathrm{mt}=314 \&$ cite $=$ williston $\& v r=2.0 \& \mathrm{rp}=\% 2 \mathrm{ffi}$ nd $\% 2$ fdefault.wl\&sp=intutrec-000>, visitado el 6 de septiembre de 2011.

${ }^{18}$ Cf. Comentario Oficial 6, sección 2-615 del Uniform Commercial Code y $§ 272$ del Restatement (Second) de Contratos.

${ }^{19}$ 499, Federal Supplement, 53, Western Distrit of Pennsylvania, 1980.

${ }^{20}$ Véase James White \& David A. Peters, “A Footnote for Jack Dawson”, in Michigan Law Review, vol. 100, N 7, Michigan, 2002, p. 1.973.

${ }^{21}$ Véase Ewoud Hondius \& Hans C. GRigoleit, Unexpected Circumstances in European Contract Law, Cambridge, Cambridge University Press, 2011.

${ }^{22}$ Véase n. 4. 
nuación de establecer la disponibilidad de una defensa basada en hardship para la parte afectada en un contrato de compraventa internacional regido por la Convención; agregó respecto del artículo 7 que

"con el objeto de integrar las lagunas de la Convención de una manera uniforme, debe recurrirse a los Principios generales que rigen el Derecho Comercial Internacional. Según tales Principios, incorporados inter alia en los Principios Unidroit sobre Contratos Comerciales Internacionales, la parte que invoca un cambio de circunstancias que altera fundamentalmente el equilibrio del contrato, está facultada para requerir su renegociación”.

En relación con lo expresado en los párrafos anteriores, la decisión de la Corte permite plantear dos conclusiones principales.

- Que la Corte estima que los "Principios generales" mencionados en el artículo 7.2 no son sólo aquéllos contenidos en la Convención misma (Principios internos) sino, también, los que pueden ser deducidos del Derecho Comercial Internacional.

- Que no obstante lo señalado en los párrafos anteriores, la Corte considera a los Principios UNIDROIT como el principal restatement de Derecho Comercial Internacional y, por tanto, la fuente principal de Principios generales en esta materia para los tribunales.

\section{IV.- El Sistema de excusas en la CONVEnción}

Para una adecuada calificación de las conclusiones antes mencionadas, es necesario analizar de manera breve el sistema de excusas contemplado en la Convención. Dicho sistema es considerado como uno de responsabilidad objetiva o estricta, ya que la parte es responsable por todos los eventos bajo la esfera de su control, independientemente de su negligencia ${ }^{23}$. Los artículos 79 y 80 contemplan la única excusa disponible para la parte que ha dejado de cumplir lo pactado: probar que su incumplimiento se debió a un impedimento más allá de su control, que fue, además, razonablemente imprevisible al momento de la celebración del contrato. Así, el artículo 79.1 dispone $^{24}$ :

"Una parte no será responsable de la falta de cumplimiento de cualquiera de sus obligaciones si prueba que esa falta de cumpli-

${ }^{23} \operatorname{LindstRÖM~(n.~8),~p.~} 2$.

${ }^{24} \mathrm{El}$ artículo 80 no será analizado, es irrelevante para el propósito de este trabajo. 
miento se debe a un impedimento ajeno a su voluntad y si no cabía razonablemente esperar que tuviese en cuenta el impedimento en el momento de la celebración del contrato, que lo evitase o superase, o que evitase o superase sus consecuencias".

Sobre la base de la norma citada, la doctrina ha establecido los siguientes requisitos para su aplicación, todos sujetos al criterio de la razonabilidad $^{25}$ :

a) La existencia de un impedimento más allá del control de la parte incumplidora.

b) Que dicho impedimento haya sido imprevisible al tiempo de la celebración del contrato.

c) Que el impedimento o sus consecuencias sean irresistibles.

De forma adicional, es importante tener presente que la aplicación de la excusa contemplada en los artículos 79 y 80 sólo implica que la parte incumplidora no será responsable de los perjuicios derivados de su incumplimiento, pero no afecta la disponibilidad para la contraparte de los otros remedios previstos por la Convención para el evento de incumplimiento $^{26}$. Sin perjuicio de ello, evidentemente lo anterior dependerá de las circunstancias del caso particular, ya que, por ejemplo, la ejecución 104 forzada puede ser imposible en caso de destrucción completa y definitiva de los bienes objeto del contrato. La razón para el establecimiento de esta norma fue generar un sistema autónomo de excusas en materia de compraventa internacional, de manera de evitar la influencia de los derechos nacionales en el caso particular ${ }^{27}$.

\section{HARDSHIP BAJO LA CONVENCIÓN}

El debido examen de la cuestión exige también analizar el papel del cambio de circunstancias en la Convención. No hay duda de que el artículo 79 es aplicable a casos de fuerza mayor, esto es, donde la ejecución de la prestación se ha vuelto absolutamente imposible. Sin embargo, el asunto se complica cuando la cuestión es determinar si la excusa prevista en el artículo 79 es también aplicable a situaciones de hardship. En esta mate-

${ }^{25}$ Véase Lindström (n. 8) y Joseph LoOKOFsky, "Impediments and Hardship in International Sales: A Commentary on Catherine Kessedjian's 'Competing Approaches to Force Majeure and Hardship", in International Review of Law and Economics, vol. 25, No 3, Copenhagen, 2005, p. 434.

${ }^{26}$ Los principales remedios disponibles para el caso de incumplimiento son la ejecución forzada, la terminación del contrato y la reducción del precio.

${ }^{27}$ Lindström (n. 8), p. 5 y Kruisinga (n. 7), p. 125. 
ria, la doctrina está dividida y la jurisprudencia es escasa para efectos de permitir una conclusión definitiva.

$\mathrm{Al}$ efecto, lo primero es determinar si la excesiva onerosidad es una excusa excluida o, incluso, rechazada (implícita o explícitamente) por la Convención. Si la respuesta es afirmativa, la parte que incumple no puede alegar hardship como justificación a su incumplimiento y es completamente responsable según las normas de la Convención. Al contrario, si se concluye que la excesiva onerosidad es una materia incluida en el ámbito de aplicación de la Convención, dos opciones son posibles:

a) La materia se encuentra regulada por el artículo 79 o, bien,

b) Siendo una materia cubierta, pero no reglada (al menos íntegramente) por la Convención, cabe aplicar el artículo 7.2, esto es, debe ser resuelta en conformidad a los Principios generales en que se basa la Convención, o a falta de tales Principios, de acuerdo con las normas de Derecho Internacional Privado aplicables al caso concreto $^{28}$.

En relación con lo anterior, una parte de la doctrina ha sostenido que el artículo 79 provee la única excusa disponible para la parte incumplidora, excusa que no incluye situaciones de excesiva onerosidad. Así, se ha indicado:

"el artículo 79 de la Convención sólo regula la imposibilidad en el incumplimiento y la mayoría de la doctrina está de acuerdo en que una circunstancia que no impide absolutamente el cumplimiento pero lo hace considerablemente más dificultoso u oneroso (por ej. en caso de cambio de circunstancias, hardship, imposibilidad económica impracticabilidad comercial, etc.) no puede ser considerada como un impedimento" 29 .

La principal razón de esta argumentación son los antecedentes históricos del establecimiento del artículo 79, que implicó que fuera redactado en términos más estrictos que su predecesor (el artículo 74 de la Ley Uniforme sobre Compraventa Internacional de La Haya), como también el rechazo de propuestas para la incorporación de una norma expresa en la materia $^{30}$. Esta doctrina rechaza, también, la aplicación del principio de

${ }^{28}$ Cf. Lindström (n. 8), pp. 11-12 y Kruisinga (n. 7), p. 153.

${ }^{29}$ Dionysios Flambouras, "Comparative Remarks on CISG Article 79 \& PECL Articles 6:111, 8:108”, in www.cisg.law.pace.edu/cisg/text/peclcomp79.html\#er, visitada el 6 de septiembre de 2011.

${ }^{30}$ Referencias en Lindström (n. 8), pp. 14-15. Sin embargo, véase Alejandro M. Garro, "Comparison between provisions of the CISG regarding exemption of liability for damages (art. 79) and the counterpart provisions of the UNIDROIT Principles (Art. 
buena fe como sustento para el reconocimiento de la excesiva onerosidad en los contratos regulados por la Convención, señalando que tal principio no puede implicar la derogación de soluciones que están contempladas de manera expresa por la Convención, la cual ha optado por un sistema unitario de excusas (artículo 79) que no incluye la excesiva onerosidad ${ }^{31}$.

$\mathrm{Al}$ contrario, otra parte de la doctrina ha sostenido que la excesiva onerosidad sí es una materia que se encuentra regida por el artículo 79 de la Convención. Los principales argumentos en este sentido se relacionan con el concepto de impedimento y la superación razonable de sus consecuencias por la parte afectada. Así, Ole Lando indica que la regla del artículo 79 es aplicable tanto a situaciones de imposibilidad absoluta como a aquéllas en que el cumplimiento se ha vuelto excesivamente gravoso de manera que sería irrazonable solicitar la ejecución del contrato según sus términos originales ${ }^{32}$. Se ha agregado que en este sentido, lo relevante es determinar el esfuerzo que puede exigirse a la parte afectada en orden a superar las consecuencias del impedimento. Así, se concluye que el artículo 79, interpretado a la luz de la buena fe en el comercio internacional, no puede entenderse como una norma que imponga a la afectada la obligación de tomar responsabilidades extraordinarias con la finalidad de cumplir lo pactado ${ }^{33}$.

106 De esta manera, el límite del sacrificio del deudor se relaciona con el principio de razonabilidad. En este sentido, John Honnold señala que el impedimento a que hace referencia el artículo 79 incluye no sólo la situación en que el cumplimiento se hace literalmente imposible,

"sino también aquella extrema dificultad en la ejecución que se equipara a la imposibilidad desde un punto de vista no técnico sino práctico" 34 .

7.1.7)", in www.cisg.law.pace.edu/cisg/text/anno-art-79.html\#uni >, IV.12, visitada el 8 de octubre de 2011, quien indica que "la historia legislativa de la Convención demuestra que las discusiones no fueron lo suficientemente concluyentes en esta materia".

${ }^{31}$ Denis Tallon, en Bianca-Bonell Commentary on the International Sales Law, Milan, Giuffrè, 1987, pp. 572-595, in www.cisg.law.pace.edu/cisg/biblio/tallon-bb79.html. En el mismo sentido Slater (n. 13), p. 259, quien establece: "ningún remedio basado en hardship está disponible [en la Convención] y la parte incumplidora no está por tanto excusada de cumplir sus obligaciones según el contrato".

${ }^{32}$ Ole Lando, Udenrigshandelens krontrakter, $3^{\mathrm{a}}$ ed., Copenhagen, DJØF Forlag, 1987, p. 299; citado por LindSTRÖM (n. 8), p. 13.

${ }^{33}$ Ibid.

${ }^{34}$ John O. Honnold, Uniform law for international sales under the 1980 United Nations Convention, $4^{\mathrm{a}}$ ed., edited and updated by Harry M. Fletchner, Alphen aan den Rijn, Kluwer Law International, 2009, p. 628, 432.2. 
Así, cumpliéndose los requisitos del artículo 79, perturbaciones y dificultades económicas pueden ser consideradas como impedimento y configurar una excusa para el deudor si son suficientemente graves o extremas. Harry Fletchner, complementando la opinión de John Honnold, indica que, si bien la excesiva onerosidad puede configurar un impedimento al tenor del artículo 79, la norma excluye la remisión al Derecho nacional, ya que regula de forma exhaustiva los efectos del impedimento sobre las obligaciones de las partes. De este modo, el sistema de remedios previsto en el artículo 79 debe prevalecer sobre cualquier otro, ya sea doctrinario o de Derecho nacional, lo que excluye, por ejemplo, la posibilidad de adaptar el contrato ${ }^{35}$.

En particular, el caso descrito en la sección II de este trabajo permite visualizar que aun aceptando que las situaciones de excesiva onerosidad no se encuentren excluidas para contratos de compraventa internacional regidos por la Convención, los resultados para las partes, en cuanto al Derecho aplicable, pueden ser muy distintos dependiendo de los argumentos que se usen para llegar a tal conclusión. Así, la Corte de Apelaciones de Amberes declaró en su fallo que los casos de hardship no estaban rechazados por la Convención, en otras palabras, eran una situación incluida, pero no prevista en la misma, que debía resolverse en conformidad con el Derecho nacional aplicable según las reglas del Derecho Internacional Privado. En consecuencia, estimó también que no existían Principios generales en los cuales se basara la Convención que permitieran resolver el caso.

Por otro lado, la sentencia emanada de la Corte de Casación belga toma una perspectiva distinta para solucionar el caso, ya que señala que las situaciones de hardship están comprendidas en el artículo 79 de la Convención, indicando:

"los cambios de circunstancias que no han sido razonablemente previsibles al tiempo de celebrar el contrato y que son de una naturaleza tal que inequívocamente tienen como consecuencia incrementar la carga del cumplimiento del contrato de una manera desproporcionada, pueden, bajo ciertas circunstancias, configurar un impedimento en el sentido que requiere el artículo 79 de la Convención”.

Este razonamiento implica que la noción de impedimento del artículo 79 es lo suficientemente amplia para incluir no sólo la imposibilidad absoluta sino, también, los casos en que el cumplimiento de la prestación se ha

${ }^{35}$ Fletchner (n. 34), pp. 630-632, 432.2. 
vuelto de forma excesiva oneroso para el deudor. Sin embargo, al mismo tiempo la Corte estimó (de modo implícito) que los casos de hardship no están completamente regulados en el artículo $79 \mathrm{y}$, por tanto, existe un vacío que debe integrarse de acuerdo con el mecanismo establecido en el artículo 7.2, esto es, recurrir a los Principios generales del comercio internacional en los cuales se basa la Convención, los que en opinión de la Corte se encuentran en lo particular contenidos en los Principios UNI$\mathrm{DROIT}^{36}$. Aplicando este último instrumento, la Corte estableció el deber de renegociación en casos de excesiva onerosidad, y ratificó la condena en perjuicios al comprador que se negó a ajustar el precio.

La decisión de la Corte de Casación belga implica aceptar la tesis que la excesiva onerosidad está contemplada en el artículo 79 de la Convención, pero no regulada (o al menos, completamente regulada) en él, lo que hace aplicable el artículo 7.2. Dicha tesis puede ser cuestionable, ya que si se estima que el concepto de impedimento del artículo 79 es lo suficientemente amplio como para incluir también las situaciones de cambio de circunstancias, entonces dicha norma debiese también ser la que rija de manera completa tales situaciones, incluyendo los efectos que prescribe para tal caso. Parece contradictorio argumentar que la excesiva onerosidad puede entrar a la Convención por la vía del artículo 79, para luego señalar que dicha materia no está de forma suficiente regulada por la norma citada y, por tanto, debe ser considerada como un vacío o laguna a integrarse según el mecanismo del artículo 7.2. Lo cierto es que el artículo 79 y la Convención en general proveen un sistema consistente y coherente de requisitos y remedios que deben aplicarse para el caso que se configure la excusa contemplada en los artículos 79 y 80, los cuales deberían regir aun si se admiten los casos de hardship.

Así, por cierto, deben cumplirse las condiciones mencionadas en la sección IV para la configuración de la excusa del artículo 79 con tal desolicitar su aplicación por la parte incumplidora. De manera evidente, tales condiciones deben ser interpretadas considerando que se trata de un caso de hardship y no de imposibilidad absoluta y, por tanto, el impedimento hará que el cumplimiento sea extremadamente oneroso, pero no imposible. En este sentido, la sentencia de la Corte de Casación de nuevo adquiere relevancia, ya que parece ser la primera que acepta que el impedimento se configure como excusa en un caso de incremento de los costos relativos a los bienes objeto del contrato, pues se ha estableci-

${ }^{36}$ La misma opinión es sostenida por GARRo (n. 30), IV.15, quien señala: "En relación con los remedios disponibles para el caso de hardship, el análisis del problema debería comenzar con el reconocimiento que esta es otra laguna 'regida pero no resuelta' que necesita ser integrada en la Convención”. 
do, por lo general, tanto por la doctrina como por la jurisprudencia, que las fluctuaciones de precios son previsibles para las partes envueltas en operaciones de contratación internacional ${ }^{37}$.

El limitar la aplicabilidad de la excesiva onerosidad a lo dispuesto por el artículo 79 no necesariamente implica perjudicar al deudor afectado, ya que esta norma establece:

"Nada de lo dispuesto en este artículo impedirá a una u otra de las partes ejercer cualquier derecho distinto del derecho a exigir la indemnización de los daños y perjuicios conforme a la presente Convención" (art. 79.5).

De esta manera, también la parte afectada por el cambio de circunstancias puede requerir la terminación del contrato y, si es procedente para superar la excesiva onerosidad, la reducción del precio del contrato. Ambos remedios pueden ser considerados, hasta cierto punto, como instrumentos para distribuir las pérdidas resultantes del cambio de circunstancias y "adaptar" el contrato a las nuevas condiciones ${ }^{38}$.

En este sentido, se ha indicado, incluso, que el remedio de la reducción del precio contemplado en el artículo 50 es un reflejo de un principio general de la Convención que implicaría el ajuste o la adaptación del contrato cuando el equilibrio de las contraprestaciones es perturbado y que puede ser usado como "un trampolín para desarrollar una regla general de adaptación del contrato en casos de hardship" ${ }^{39}$. Asimismo, el

${ }^{37}$ Referencias a la jurisprudencia pueden consultarse en Ingeborg ScHwEnzER, "Force Majeure and Hardship in International Sales Contracts", in Victoria University of wellington Law Review, No 39, London, 2008, p. 709, quien señala además: "todas las decisiones referidas a hardship en relación con el artículo 79 establecen que incluso un incremento o disminución de precios de más de 100\% no es suficiente". Al efecto, debe recordarse que en el caso mencionado en el cuerpo de este artículo, el incremento de precio fue aproximadamente de un $70 \%$.

${ }^{38}$ En este sentido, se ha señalado: "el artículo 79(5) de la Convención puede ser usado para abrir la posibilidad a un juez o tribunal arbitral para determinar lo que las partes se deben recíprocamente, 'adaptando' así los términos del contrato a las nuevas circunstancias. Además de la indemnización de perjuicios, un tribunal puede decretar, si se justifica según las reglas de la Convención, la terminación del contrato desde una determinada fecha. Por cierto, es imposible recurrir al cumplimiento forzado del contrato, pero un método flexible para ajustar sus términos puede lograrse recurriendo a la reducción del precio según el artículo 50 de la Convención”, Garro (n. 30), IV.16.

${ }^{39}$ Peter Schlechtriem, extracto de "Transcript of a Workshop on the Sales Convention: Leading CISG scholars discuss Contract Formation, Validity, Excuse for Hardship, Avoidance, Nachfrist, Contract Interpretation, Parol Evidence, Analogical Application, and much more", transcribed and edited by Harry M. Flechtner, in http://cisgw3.law. pace.edu/cisg/biblio/workshop-79.html, visitada el 5 de agosto de 2011. En todo caso, el citado autor califica sus conclusiones como especulativas. 
principio de buena fe ha sido usado para establecer una obligación de cooperación entre las partes, que incluye la eventual adaptación del contrato en situaciones excepcionales de cambio de circunstancias, y que incluye el conceder a los tribunales la facultad de adaptar el contrato mediante la interpretación de la voluntad de las partes a la luz del mencionado principio de buena $\mathrm{fe}^{40}$.

\section{El deber de Renegociación en los PRincipios UNIDROIT}

Como se ha indicado, el remedio que la Corte de Casación belga estimó procedente para el caso excesiva onerosidad de una compraventa internacional fue el deber de renegociación que nace para ambas partes. A continuación, se analizarán en más detalle las características de dicho deber según lo contemplan los Principios UNIDROIT.

Los mencionados Principios se refieren al deber de renegociación en el contexto de la regulación de hardship en los artículos 6.2.1 a 6.2.3 y, en particular, en la última norma citada, que se refiere a sus efectos:

"Efectos de la "excesiva onerosidad (hardship): (1) En caso de 'excesiva onerosidad' ( hardship), la parte en desventaja puede reclamar la renegociación del contrato. Tal reclamo deberá formularse sin demora injustificada, con indicación de los fundamentos en los que se basa. (2) El reclamo de renegociación no autoriza por sí mismo a la parte en desventaja para suspender el cumplimiento. (3) En caso de no llegarse a un acuerdo dentro de un tiempo prudencial, cualquiera de las partes puede acudir a un tribunal. (4) Si el tribunal determina que se presenta una situación de 'excesiva onerosidad' (hardship), y siempre que lo considere razonable, podrá: (a) resolver el contrato en fecha y condiciones a ser fijadas; o (b) adaptar el contrato con miras a restablecer su equilibrio".

Así, los Principios, siguiendo la opinión de una destacada doctrina que estima que en materia de Derecho Comercial Internacional el deber de renegociar el contrato de buena fe en casos de excesiva onerosidad es una regla de la lex mercatoria ${ }^{41}$, han establecido como primer derecho (y deber) de la parte afectada por un cambio de circunstancias, el requerir

${ }^{40}$ Referencias en Kruisinga (n. 7), p. 150.

${ }^{41}$ Véase Michael Mustill, "The New Lex Mercatoria: The First Twenty-five Years", in Arbitration International, New York, 1988, pp. 86 et seq. y Andreas F. Lowenfeld, "Lex Mercatoria: An Arbitrator's View”, in Arbitration International, New York 1990, p. 133 et seq. 
a la otra la renegociación del contrato con el objetivo de adaptarlo a las nuevas condiciones.

No obstante lo expresado, otra parte de la doctrina ha sostenido que los Principios no establecen la obligación o el deber de renegociar los términos del contrato para la parte favorecida por la excesiva onerosidad, en especial si se comparan las disposiciones de los Principios UNIDROIT con el artículo 6:111 de los PECL, que establece de manera expresa que éstas tienen la obligación de negociar una adaptación del contrato si su cumplimiento resulta excesivamente gravoso ${ }^{42}$. Sin embargo, dicho argumento no es plena del todo convincente, ya que el artículo 6.2.3 expresamente faculta a la parte afectada a requerir la renegociación del contrato $^{43}$. En la práctica, no es necesario facultar a ninguna de las partes para solicitar la renegociación del contrato, pues ellas siempre podrán hacerlo, aun en caso que no exista hardship. La mención expresa en la norma, entonces, sólo puede tener sentido si se interpreta como otorgando a la parte afectada un derecho a requerir la renegociación del contrato, lo que implica que la parte aventajada tiene un deber de renegociar, todo ello, por cierto, bajo los imperativos de la buena fe, según se explicará más adelante. Además, también puede alegarse en favor de la existencia del deber de renegociación, que el artículo 6.2.3 se refiere en general a los efectos de la excesiva onerosidad, es decir, a las consecuencias jurídicas que se producen en tal caso. Los comentarios oficiales de los Principios confirman también esta interpretación, ya que de forma expresa indican: "la parte afectada no pierde su derecho a reclamar la renegociación por el hecho de haber actuado con demora injustificada" ${ }^{44}$. Doctrina autorizada tampoco cuestiona la existencia de este deber. Así, Michael Bonell señala:

"el artículo 6.2.3 (efectos de la excesiva onerosidad) concede a la parte afectada el derecho a requerir la renegociación del contrato con el objeto de adaptar sus términos a las nuevas circunstancias" ${ }^{\$ 5}$.

${ }^{42}$ Ewan McKendrick, "Section 2: Hardship”, in Stefan Vogenauer \& Jan KLeinheisterkamp (ed.), Commentary on the Unidroit Principles of International Commercial Contracts (PICC), Oxford, Oxford University Press, 2009, p. 722 y Draft Common Frame of Reference, V. I, Comentarios oficiales al artículo III.- 1:110, 713. Adicionalmente, en el caso de los PECL, el incumplimiento de la obligación de renegociar está sancionado con un remedio específico, cual es la indemnización de perjuicios (inciso final del art. 6:111).

${ }^{43}$ La versión en inglés de los Principios es aún más útil para construir el argumento, ya que en ella el artículo 6.2.3(1) primera parte indica: "In case of hardship the disadvantaged party is entitled to request renegotiations". La cursiva es nuestra.

${ }^{44}$ Principios UNIDROIT, versión 2004, p. 197. La cursiva es nuestra.

${ }^{45}$ Michael J. Bonell, An International Restatement of Contract Law, $3^{\mathrm{a}}$ ed., New York, Transnational Publications, 2005, p. 118. La cursiva es nuestra. 
Por último, fallos arbitrales de la ICC han reconocido también la existencia de un deber de renegociar el contrato según los artículos 6.2.2 y 6.2.3 de los Principios UNIDROIT ${ }^{46}$.

En cuanto al contenido del deber de renegociación, la aplicación del principio de buena fe se concreta en una serie de conductas particulares que deben ser observadas por las partes. Así, en primer lugar, la parte afectada por la excesiva onerosidad debe requerir la renegociación del contrato en el más breve plazo y sin demora injustificada. Los criterios esenciales para determinar en el caso particular la oportunidad del requerimiento serán la naturaleza de la obligación que se ha tornado excesivamente onerosa y las circunstancias que han causado tal onerosidad. Tal requerimiento, además, debe estar fundado en cuanto a la existencia de las circunstancias sobrevinientes que afectan el contrato y la manera en que tales circunstancias transforman la prestación de la parte afectada en excesivamente onerosa, de modo que la contraparte cuente con información suficiente para analizar el derecho de la otra a solicitar la renegociación. En segundo lugar, propuestas y contrapropuestas deben ser serias, razonables y coherentes, proveyendo la información necesaria para un claro entendimiento por la parte contraria. Además, el deber de cooperación mutuo implica que las partes deben conducir las negociaciones con flexibilidad y tomando en consideración no sólo sus intereses sino los de su contraparte, evitando, por tanto, las dilaciones injustificadas como el término abusivo o intempestivo de las negociaciones ${ }^{47}$.

Respecto a la extensión del período de renegociación del contrato, los Principios UNIDROIT se refieren a un "período razonable" para efectuar las negociaciones y llegar a un acuerdo. La fórmula parece adecuada si la vinculamos a la naturaleza y complejidad del contrato en el caso particular, así como a otras circunstancias externas verificables de forma objetiva

${ }^{46} 2000$ Arbitral Award ICC International Court of Arbitration ( $\left.\mathrm{N}^{\circ} 10021\right)$ y December 2001 Arbitral Award ICC International Court of Arbitration ( $N^{\circ}$ 9994), citados en Michael J. Bonell (ed.), The UNIDROIT Principles in Practice, $2^{\text {a }}$ ed., Ardsley, Transnational Publishers, 2006, pp. 337, 817, 985. En la última decisión citada, el tribunal señaló expresamente que el deber de renegociar en caso de excesiva onerosidad "prevalece también en derecho comercial internacional (véanse los artículos 6.2.2 y 6.2.3 de los Principios UNIDROIT)".

${ }^{47}$ En materia arbitral se ha señalado que el principio de conducir las negociaciones de buena fe supone "el mantenimiento de la negociaciones por un período adecuado a las circunstancias, la consideración de los intereses de la contraparte y la búsqueda persistente de un acuerdo razonable" p. 59, Kuwait vs. American Independent Oil Company. El tribunal arbitral citó en su fallo la decisión de la Corte Internacional de Justicia en los casos North Sea Continental Shelf : “... (las partes) están sujetas a la obligación de comportarse de manera que las negociaciones sean serias, lo que no ocurre cuando cualquiera de ellas insiste en su propio planteamiento sin contemplar modificación alguna en él". International Court of Justice Reports, 1969, pp. 47-48. 
como, por ejemplo, la lejanía física de los contratantes o su estructura jurídica en cuanto a los procesos de toma de decisiones vinculantes. Por otra parte, en relación con la exigibilidad de las prestaciones durante el período de renegociaciones, como principio general puede establecerse que el contrato se mantiene vigente a menos que las partes acuerden expresamente lo contrario. Solo en circunstancias muy excepcionales puede permitirse a la parte afectada suspender el cumplimiento de sus obligaciones. Así lo establecen los Principios en su artículo 6.2.3.

Concluido el período de renegociación, las opciones se reducen a dos: las partes han logrado llegar a un acuerdo, y el contrato se modificará según los términos de dicho acuerdo o, bien, la renegociación puede fracasar, sin que las partes lleguen a acuerdo sobre una adaptación del contrato a las nuevas circunstancias. En este último caso, es importante distinguir si las partes han actuado de buena o mala fe.

Si las partes han actuado de buena fe durante el proceso de renegociación, pero fracasa debido a legítimas discrepancias que les impidan llegar a un acuerdo, pues no hay incumplimiento de algún deber de conducta u obligación, los efectos del fracaso de las negociaciones se reducen a la extinción del contrato o a su adaptación por el juez (artículo 6.2.3 de los Principios).

En cambio, si ha sido la actuación de mala fe de una de las partes la que ha impedido el acuerdo, o si simplemente una de las partes se ha negado de forma injustificada a renegociar el contrato, la otra tiene derecho a demandar los perjuicios que de tal actuación se deriven, además de la resolución del contrato ${ }^{48}$. Si bien ello no está establecido expresamente en los Principios, puede colegirse como consecuencia natural de la infracción voluntaria de un deber de conducta por la parte que ha actuado de mala fe. Así lo dispone la norma correspondiente de los PECL (inciso final del artículo 6:111) al estipular:

“el juez o tribunal podrá ordenar que la parte que se negó a negociar o que rompió dicha negociación de mala fe, proceda a reparar los daños causados a la parte que sufrió dicha negativa o dicha ruptura".

La decisión de la Corte de Casación belga sigue la opinión que la normativa sobre hardship de los Principios UNIDROIT establece como primer efecto de la excesiva onerosidad un deber de renegociación para

${ }^{48}$ La ejecución forzada del deber de renegociar no parece una alternativa realista, ya que al tratarse de una obligación de hacer implica la realización de una conducta personal que no es posible de obtener coercitivamente. 
las partes. Asimismo, confirma también que la negativa injustificada a renegociar una propuesta justa y razonable implica el incumplimiento de tal deber, y en general, la violación al deber general de actuar de buena fe. Finalmente, también acorde con lo expresado en los párrafos anteriores, como remedio para tal incumplimiento, la Corte establece la indemnización de perjuicios a favor de la parte afectada por la excesiva onerosidad, y que ha requerido de buena fe la renegociación del contrato. En cuanto al monto de los perjuicios, la Corte indica que ellos deben determinarse sobre la base del eventual éxito de las negociaciones, si ellas se hubieren desarrollado de buena fe por ambas partes, aun cuando en la práctica deba recurrirse a la equidad para la determinación concreta del monto a indemnizar, debido a la incertidumbre respecto de los términos efectivos de modificación del negocio que hubiesen resultado de una renegociación exitosa.

Queda por resolver una cuestión compleja respecto de la satisfacción de la conducta de buena fe de la parte aventajada en la renegociación, cual es si tal deber se satisface con el simple hecho de aceptar (de buena fe) el requerimiento de renegociación del contrato efectuado por la parte afectada por la excesiva onerosidad; o si la parte aventajada debe también aceptar una propuesta justa y razonable de adaptación del contrato

114 a las nuevas circunstancias. Si bien, parte minoritaria de la doctrina ha sostenido esta última posición ${ }^{49}$, razones de fondo y de carácter práctico hacen dudosa si procedencia. Al efecto, el autor estima que lo esencial es analizar la buena o mala fe de la parte a la cual se dirige la propuesta, de manera de determinar sobre la base de dicha conducta las consecuencias del fracaso de las negociaciones, las cuales, como se señaló, pueden incluir la indemnización de perjuicios y la resolución del contrato. Asimismo, el interés de la parte afectada se protege adecuadamente, ya que si desea perseverar en el contrato (modificado), el problema se soluciona concediendo al juez la facultad de revisarlo, pudiendo considerar como alternativa válida para su adaptación la propuesta rechazada ${ }^{50}$.

De los hechos descritos en el fallo, parece ser que la parte aventajada (el comprador), rechazó sistemáticamente las propuestas de ajuste del precio planteadas por la contraparte, insistiendo en la ejecución del contrato según sus términos originales. Este comportamiento fue considerado

${ }^{49}$ Bruno Oppetit, "L'adaptation des contrats internationaux aux changements de circonstances: la clause de 'hardship?", in Journal du Droit International, 1974, pp. 794, 807; Richard E. Speidel, “Court-Imposed Price Adjustments Under Long-Term Supply Contracts", in Northwestern University Law Review, N 76, 1981, p. 369.

${ }^{50}$ Para un análisis detallado de la cuestión, véase Rodrigo MOMBERG, "La revisión del contrato por las partes: el deber de renegociación como efecto de la excesiva onerosidad sobreviniente", en Revista Chilena de Derecho, vol. 37, Valdivia, 2010, pp. 43-72. 
por la Corte como suficiente para constituir una infracción al deber de renegociar de buena fe en caso de excesiva onerosidad. Lamentablemente no hay mención expresa en el fallo respecto de si estos rechazos (o las propuestas) fueron o no justificados. En todo caso, debe precisarse que para considerar el rechazo de un requerimiento de renegociación como constitutivo de abuso o mala fe, éste al menos debe ser debe ser injustificado de forma evidente a la luz de la razonabilidad de la propuesta y la evidencia en el caso concreto de las circunstancias que han tornado la obligación de la contraparte excesivamente onerosa, trastornando de manera grave el equilibrio económico del contrato.

\section{CONCLUSIONES Y PERSPECTIVAS PARA El DERECho NACIONAL}

El propósito de la Convención, de promover la uniformidad en su aplicación, es de la mayor relevancia y no debe ser obviado por los tribunales. En este sentido, parece mejor recurrir para su integración a los Principios generales en los cuales la Convención se basa, y tratar de evitar la referencia al Derecho interno. En particular, la materia relativa a la excesiva onerosidad presenta aún diferencias notables en el ámbito jurisdicciones nacionales, por lo que es preferible recurrir a instrumentos de Derecho uniforme, no obstante tengan la naturaleza de codificaciones doctrinales o no legislativas, pero que gozan de amplio reconocimiento por parte de la comunidad jurídica a la cual están dirigidas ${ }^{51}$.

Así, parece razonable la opción de la Corte de Casación belga de recurrir a los Principios UNIDROIT en materia de hardship. Aun cuando sea discutible que tales Principios reflejen, a su vez, los Principios generales en los cuales la Convención se basa, en particular respecto de la excesiva onerosidad, tal opción presenta ventajas que la hacen aconsejable. La Convención adolece de las deficiencias propias de su naturaleza jurídica: al ser una convención internacional, es el producto de compromisos ineludibles y su actualización es extremadamente difícil. La única forma de evitar que la Convención se transforme en un instrumento estático y obsoleto es por medio de la incorporación de instituciones modernas, pero al mismo tiempo fundadas en doctrina y jurisprudencia. Sería un error el interpretar de forma literal los términos de su artículo 7.2 ("los Principios generales en los que se basa la presente Convención") en el sentido de restringir su significado sólo a Principios que existían al tiempo en que la Convención fue adoptada.

\footnotetext{
${ }^{51}$ Véase Jansen (n. 1).
} 
En particular, respecto de la excesiva onerosidad, si bien al tiempo de adoptarse la Convención (1980) ya era reconocida en diversas jurisdicciones, puede estimarse que tal reconocimiento era bastante menor al que existe hoy día, en especial si se examina el Derecho Positivo. Por ejemplo, dicha doctrina fue incorporada en 1992 en el nuevo Código Civil holandés y en el año 2002 al $B G B$ (sin perjuicio de su previo y amplio reconocimiento jurisprudencial en este último país). También en Europa, los proyectos de reforma al Código Civil francés y español la reconocen expresamente. ${ }^{52}$ Esta tendencia ha sido seguida en Latinoamérica, donde la doctrina de la imprevisión ha sido reconocida en el último tiempo en los Códigos Civiles de Perú (1984), Paraguay (1987) y Brasil (2003), entre otros $^{53}$. Por otro lado, la primera edición de los Principios UNIDROIT es del año 1994 y la de los PECL del año 1995.

Sin perjuicio de lo anterior, es claro que la excesiva onerosidad sigue siendo una materia polémica y no resuelta en relación con la compraventa internacional de mercaderías ${ }^{54}$. Esta situación demuestra que la opción de los redactores de la Convención de excluir su regulación no fue la mejor, porque ha dejado demasiado espacio para interpretaciones divergentes. No es realista asumir que siempre las partes incluirán en el contrato cláusulas expresas de hardship o similares. Al contrario, una serie de factores pueden impedir la inclusión de tales cláusulas como, por ejemplo, si las éstas no son lo suficientemente sofisticadas o si el negocio debe cerrarse en un plazo breve que no permite más que el acuerdo en sus elementos esenciales.

Por último, algunas reflexiones respecto de la situación del Derecho nacional. El establecimiento de la existencia de un deber de renegociación en materia de compraventa internacional de mercaderías para el caso de

${ }^{52}$ Véase en general, John Cartwright, Stefan Vogenauer \& Simon Whittaker (eds.), Reforming the French Law of Obligations, Comparative Reflections on the Avant-projet de réforme du droit des obligations et de la prescription ('the Avant-projet Catala', Oxford and Portland, Hart Publishing, 2009; François Terré (dir.), Pour une réforme du droit des contrats, Paris, Dalloz, 2008. El Proyecto de Reforma Español está disponible en /www.mjusticia.es/cs/Satellite ?blobcol=urldescarga $1 \&$ blobheader $=$ application $\% 2$ Fpdf\&blobkey=id\&blobtable $=$ Suple mentoInformativo\&blobwhere $=1161679155283 \&$ ssbinary $=$ true

${ }^{53}$ La excesiva onerosidad ya había sido reconocida en el Código Civil de Argentina en 1968. En Europa, la situación es similar en el caso de Italia, habiendo sido la materia incluida en el Codice Civile de 1942.

${ }^{54}$ Cf. Lindstrom (n. 8), p. 22, señala: "el artículo 79 es un ejemplo camaleónico de armonía superficial" y que "es posible de interpretar de manera que acomode mejor a la formación del intérprete". En el mismo sentido, TALLON (n. 31), "la redacción general del artículo 79 deja mucho espacio para la interpretación judicial”; y HonNOLD (n. 34), pp. 627, 432.1. "el artículo 79 puede ser la norma menos exitosa de la Convención como parte de medio siglo de trabajo hacia la uniformidad internacional". 
excesiva onerosidad sobrevenida, refuerza la tendencia general hacia el reconocimiento de dicha institución jurídica en el Derecho contemporáneo y la conveniencia que ello también suceda en nuestro ordenamiento. En concreto, la resolución del caso particular por la Corte de Casación belga puede resultar atractiva para nuestra jurisprudencia, renuente a intervenir en el acuerdo de las partes. Al resolver que existía un incumplimiento del deber de renegociar el acuerdo por la parte aventajada por la excesiva onerosidad y decretar la indemnización de perjuicios en favor de la contraparte, el contrato no fue modificado ni adaptado a las nuevas circunstancias ${ }^{55}$. Formalmente, entonces, el negocio se mantuvo según sus términos originales, preservándose desde este punto de vista el principio de la fuerza obligatoria del contrato o pacta sunt servanda, aun cuando en la práctica el resultado fue similar al de un ajuste del precio.

Aún más, considerando que la Convención es derecho vigente en nuestro país, el considerar que la excesiva onerosidad puede ser aplicada en contratos regidos por ella puede estimarse como una puerta abierta que facilite su reconocimiento por los tribunales nacionales, hasta ahora contrarios a ello ${ }^{56}$. En este sentido, los Principios UNIDROIT, los PECL y el Borrador de Marco Común de Referencia son instrumentos útiles (y quizá de referencia ineludible) para una formulación moderna de la antigua cláusula rebus sic stantibus.

\section{BibLIOGRAFÍA}

Beale, Hugh G., William D. Bishop \& Michael P. Furmston, Contract, Cases and Materials, $4^{\mathrm{a}}$ ed. London, Butterworths, 2001.

Bonell, Michael J., "The UNIDROIT Principles of International Commercial Contracts and CISG-Alternatives Or Complementary Instruments?", in Uniform Law Review, No 1, 1996.

Bonell, Michael J., An International Restatement of Contract Law, $3^{\text {a }}$ ed., New York, Transnational Publications, 2005.

Bonell, Michael J. (ed.), The UNIDROIT Principles in Practice, $2^{\mathrm{a}}$ ed., Ardsley, Transnational Publishers, 2006.

Cartwright, John, Stefan Vogenauer \& Simon Whittaker (eds.), Reforming the French Law of Obligations, Comparative Reflections on the Avant-projet de réforme du droit des obligations et de la prescription ('the Avant-projet Catala'), Oxford and Portland, Hart Publishing, 2009.

${ }^{55}$ Debe recordarse que los bienes objeto de la compraventa ya habían sido entregados.

${ }^{56}$ Cf. Rodrigo Momberg, "Teoría de la imprevisión: la necesidad de su regulación legal en Chile", en Revista Chilena de Derecho Privado, N 15, Santiago, diciembre 2010, pp. 29-64. 
Flambouras, Dionysios, "Comparative Remarks on CISG Article 79 \& PECL Articles 6:111, 8:108", in www.cisg.law.pace.edu/cisg/text/peclcomp79.html\#er.

Garro, Alejandro M., "Gap-Filling Role of the Unidroit Principles in International Sales Law: Some Comments on the Interplay between the Principles and the CISG”, in Tulane Law Review, Nº 69, New Orleans, 1994.

Garro, Alejandro M., "Comparison between provisions of the CISG regarding exemption of liability for damages (Art. 79) and the counterpart provisions of the UNIDROIT Principles (art. 7.1.7)", in www.cisg.law.pace.edu/cisg/ text/anno-art-79.html\#uni.

Hondius, Ewoud \& G. Hans C. Rigoleit, Unexpected Circumstances in European Contract Law, Cambridge, Cambridge University Press, 2011.

HoNNOLD, John O., Uniform law for international sales under the 1980 United Nations Convention, $4^{\mathrm{a}}$ ed., edited and updated by, Harry M. Fletchner, Alphen aan den Rijn, Kluwer Law International, 2009.

Jansen, Nils, The making of legal authority: non-legislative codifications in historical and comparative perspective, Oxford, Oxford University Press, 2010.

Kruisinga, Sonja, (Non-) Conformity in the 1980 UN Convention on Contracts for the International Sale of Goods: A Uniform Concept?, Amberes, Intersentia Uitgevers NV, 2004.

Kull, Andrew, "Mistake, Frustration, and the Windfall Principle of Contract Remedies", in Hastings Law Journal, N 43, London, 1991.

LANDO, Ole, Udenrigshandelens krontrakter, $3^{\mathrm{a}}$ ed., Copenhagen, DJØF Forlag, 1987.

Lindström, Niklas, "Changed Circumstances and Hardship in the International Sale of Goods", in Nordic Journal of Commercial Law, Estambul, 2006.

Lookofsky, Joseph, "Impediments and Hardship in International Sales: A Commentary on Catherine Kessedjian's 'Competing Approaches to Force Majeure and Hardship", in International Review of Law and Economics, vol. $25, \mathrm{~N}^{\mathrm{o}} 3$, ciudad, 2005.

Lowenfeld, Andreas F., "Lex Mercatoria: An Arbitrator's View", in Arbitration International, Copenhagen, 1990.

MCKENDRICK, Ewan, "Frustration and Force Majeure-Their Relationship and Comparative Assessment", in Ewan Mckendrick (ed.), Force Majeure and Frustration of Contract, London, Lloyd's of London Press Ltd., 1991.

MCKENDRICK, Ewan, "Section 2: Hardship", in ed. Stefan Vogenauer \& Jan KLeINHeISTERKAmP, Commentary on the Unidroit Principles of International Commercial Contracts (PICC), Oxford, Oxford University Press, 2009.

Momberg, Rodrigo, "La revisión del contrato por las partes: el deber de renegociación como efecto de la excesiva onerosidad sobreviniente”, en Revista Chilena de Derecho, vol. 37, Valdivia, 2010.

Momberg, Rodrigo, "Teoría de la imprevisión: la necesidad de su regulación legal en Chile", en Revista Chilena de Derecho Privado, $\mathrm{N}^{\circ} 15$, Santiago, diciembre 2010. 
Mustill, Michael, “The New Lex Mercatoria: The First Twenty-five Years”, in Arbitration International, New York, 1988.

Oppetit, Bruno, "L'adaptation des contrats internationaux aux changements de circonstances: la clause de "hardship", in Journal du Droit International, 1974.

Schlechtriem, Peter, extracto de "Transcript of a Workshop on the Sales Convention: Leading CISG scholars discuss Contract Formation, Validity, Excuse for Hardship, Avoidance, Nachfrist, Contract Interpretation, Parol Evidence, Analogical Application, and much more", transcribed and edited by Harry M. Flechtner, in http://cisgw3.law.pace.edu/cisg/biblio/workshop-79.html.

Schwenzer, Ingeborg, "Force Majeure and Hardship in International Sales Contracts", in Victoria University of wellington Law Review, No 39, London, 2008.

SLATER, Scott D., "Overcome by Hardship: The Inapplicability of the UNIDROIT Principles' Hardship Provisions to CISG”, in Florida Journal of International Law, No 12, Florida, 1998.

SpeIDEL, Richard E., "Court-Imposed Price Adjustments Under Long-Term Supply Contracts", in Northwestern University Law Review, No 76, 1981.

TAllon, Denis, in Bianca-Bonell Commentary on the International Sales Law, Milan, Giuffrè, 1987, in http://www.cisg.law.pace.edu/cisg/biblio/tallon-bb79.html.

Terré Fraçois (dir.), Pour une réforme du droit des contrats, Paris, Dalloz, 2008.

Treitel, Guenter, Frustration and Force Majeure, $2^{\mathrm{a}}$ ed, London, Sweet \& Maxwell Limited, 2004.

VIDAL, Álvaro, "Integración de la Convención de Viena sobre Compraventa Internacional de Mercaderías", en Revista de Derecho PUCV, vol. xxIV, Valparaíso, 2003.

White James \& David A. Peters, “A Footnote for Jack Dawson”, in Michigan Law Review, vol. 100, N 7, Michigan, 2002.

Williston, Samuel \& Richard A. LorD, Williston on Contracts, in http://international.westlaw.com/find/default.wl?rs=WLIN10.08\&ifm= NotSet\&fn=_top\& $\mathrm{sv}=$ Split\&findjuris $=00001 \& \mathrm{mt}=314 \&$ cite $=$ williston $\& v \mathrm{r}=2.0 \& \mathrm{rp}=02 \mathrm{ffind} \% 2 \mathrm{f}$ default.wl\&sp=intutrec-000>. 